A hipótese básica deste trabalho é que, na próxima década, admitindo-se a cláusula coeteris paribus, continuará a corrida por inovações tecnológicas: tecnologias em uso continuarão a reestruturar indústrias e mercađos, enquanto inovaçőes tecnológicas criarão novos mercados e novas indústrias para servi-los.

Admitida a hịpótese - e parece que existem evidênrias suficientes para sustentá-la - infere-se que nenhuma empresa poderá ignorar as transformações tecnológicas

\section{Inovação tecnológica e planejamento estratégico na década de 80}

Henrique Rattner

Professor titular no Departamento de Fundamentos Sociais e Jurídicos da Administração (FSJ), da
EAESP/FGV.

O ensino convencional de administração e planejamento de empresas tem enfatizado o equacionamento e a análise dos fatorés de produção, investimento, potencial de mercado, energia, disposiçð̄es e regulamentos governamentais sem, todavia, prestar muita atenção a uma dimenstóo dos negócios que se tomou crucial para a so brevivência das empresas - a inovação tecnológica.

A tecnologia assume orescentemente um papel estratégico, tão essencial ao sucesso da firma quanto o capital, sua capacidade organizacional, produtiva e de man keting.

Contudo, diferentemente dos outros, a posição estratégica da empresa no domínio tecnológico pode mudar rapidamente, tornando-se de líder de seu mercado em mera seguidora dependente.

Vivemos uma era de mudanças tecnologicas rápidas e intensas que se processam em escala global. Indústrias baseadas em alta tecnologia tendem a conquistar e a expandir-se em mercados globais.

Por isso, parece imprescindível a familiarização dos executivos e planejadores, de empresas privadas e públicas, com as tendências e forças que induzem mudanças tecnologicas nos mercados de escala global, no sistema econômico contemporâneo.

Na década de 70, observou-se o avanço e a expansto comercial de novas tecnologias, tais como a eletrônica do estado sólido e os microprocessadores com enorme capacidade de armazenamento e operaçá, bem como a rápida maturação de outras, como, por exemplo, a geração de energia nuclear, que parecia extremamente promissora, ainda há poucos anos. Esșas mudanças tecnológicas tendem a imprimir novos padróes de comportamento ds empresas e aos govemos e a provocar impacto em diversos níveis de vida econômica e política. que se processam em seu ramo e, tampouco, as escolas de economia e administração podem omitir-se de uma análise crítica e, eventualmente, de um exercício de prospectiva dessas tendências, em função de seus impactos sobre a sociedade.

Tentaremos apontar e analisar, de forma sucinta, algumas tendências; cujas conseqüências far-se-ão sentir em escala global, ha década de 80 :

a) na medida em que aumente a importância estratégica da tecnolögia, de sua administração dependerá, crescentemente, o- sucesso ou fracasso da empresa, mesmo em ramos nẫo considerados de "alta" tecnologia;

b) mudanças significativas se processam; via "deslocamento" tecnológico, em ramos e mercados maduros e tradicionais;

c) novas tecnologias emergentes estão criando novas iridustrias e, portanto, novas oportunidades de mercado, enquanto alteram, em mercados tradicionais, os padröes de concorrência, derrubando empresas líderes tradicionais;

d) a concorrência desenfreada por mercados em escala global está sendo estimulada pelas-novas tecnologias e toma-se necessidade pelos elevados custos de seu desenvolvimento;

e) por motivos econômicos e políticos uma onda de "nacionalismo tecnológico" está se expandindo, levando os governos a dar apoio "e proporcionar estímulos e incentivos diferentes a competiçáo tecnológica, nos mercados, particularmente nos NIC . (Newly Industrialized Countries), onde surgiram, nos últimos anos, diversas tentativas de implantar políticas tecnologicas "explicitas";

f) mudanças no processo de produção e na administração de empresas estáo levando as sociedades a uma encruzilhada que exige a formulaça de um projeto social alternativo. acima:

Comentaremos a seguir as tendências enameradas

a) o papel estratégico crescente da tecnologia: o desenvolvimento de novas tecnologias e suas aplicaçōes tendem a afetar um número de indústrias e atividades crescentes. Postulando a continuidade das tendências verificadas nas décadas de 60 e 70, é lícito antecipar trans formaçóes significativas nos anos 80 .

Assim, o ramo editorial de livros e revistas, a imprensa e o setor grafico em geral estão sendo reestrutu. 
rados completamente, tornando-se parte da "indústria de informação" emergente.

Nò setor bancário, os executivos encaram a tecnologia como um dos três fatores fundamentais de seus-negócios, sendo os outros dois os regulamentos mutantes em decorrência das políticas monetárias-fiscais do governo e a concorrência de conglomerados financeiros diversificados.

Bens de consumo, comunicações pessoais e programas de entretenimento estão sendo afetados pela difusão de novas tecnologias, especialmente daquelas baseadas na microeletrônica.

Por sua capacidade de induzir mudanças estruturais fundamentais a nivel da organização e da produção da empresa, a tecnologia passa a ser considerada um fator estratégico e, portanto, deve ser integrado no processo de planejamento a médio e longo prazos da empresa.

b) mudanças desestabilizadoras em indústrias tradicionais: a segunda tendência, resultado da importância crescente da tecnologia, é representada pelas transformaçōes que ocorrem nas indústrias tradicionais, nas quais a mudança tecnológica tem sido relativamente lenta. Em alguns casos, essas indústrias (câmeras fotográficas, bens de consumo eletrônico etc.) estão sendo redefinidas pela incorporação de novas tecnologias, geralmente desenvolvidas em outras indústrias, menos maduras, e cuja aplicação - uma vez transferidas - se verifica a uma velocidade espantosa.

A adoção por empresas atuando em mercados tradicionais, de tecnologia cujas vantagens foram demonstradas em outros ramos ou mercados, pode ser denominada de "deslocamento de tecnologia". O uso crescente de microprocessadores e de outros equipamentos eletrôni$\cos$ ou a introdução de plásticos como sucedâneos de metais na indústria automobilística constituem exemplos de "deslocamento de tecnologia". Uma série de indústrias tradicionais está sendo afetada pelas novas tecnologias, conforme a figura 1, incluindo telecomunicações, gráfica e editorial, máquinas-ferramenta, automobilística e o setor financeiro.

Figura 1

A tecnologia transforma ramos e mercados tradicionais

Exemplos de ramos/mercados

Mudanças Tecnológicas Significativas

Automobilístico

Bancos c seguros

Telecomunicaçōes telefone

Eletrônica, substituição de materiais

Eletrônica, sistemas de telecomunicações, sistemas de cartões de crédito

Publicações

Fusão de computadores com comunicações

Bancos de dados eletrônicos, sistemas de composição c produção acoplados a computadores; sistemas gráficos bascados $\mathrm{cm}$ laser

Produção industrial em geral
Vale a pena ressaltar que empresas operando em mercados tradicionais serăo provavelmente as mais vulneráveis à pressão competitiva de firmas entrantes, baseadas na tecnologia de ponta. Demorar demais na tecnologia tradicional resultará, invariavelmente, em prejuizos e perda de fatias do mercado. Um exemplo típico a este respeito é oferecido pelo setor bancário, em que a introdução de equipamentos eletrônicos permite, segundo estimativas, uma redução dos custos operacionais de, aproximadamente, $30 \%$.

A emergência de novas tecnologias, como fator critico, constitui um desafio para os executivos engajados no planejamento a médio e longo prazos.

c) a tecnologia revoluciona indústrias: enquanto algumas inovaçð̋es tecnológicas desestabilizam ramos tradicionais, em outras elas têm efeitos revolucionários. A tecnologia do semicondutor, por exemplo, ampliou a quantidade de "inteligência" que pode ser instalada em equipamentos, tais como controles industriais, minicomputadores e máquinas de comando numérico.

As mudanças introduzidas nos processos de produção e nos produtos permitem antecipar uma reestruturação dos negócios, não somente dos produtores, mas também dos usuários do equipamento manufatureiro.

As múltiplas aplicações do microprocessador combinam-se para reduzir os custos a niveis mais baixos, induzindo a ampliação e expansão de suas aplicaçōes, em escala crescente (ver figura 2 ).

Figura 2

A tecnologia revoluciona indústrias baseadas em tecnologia de ponta

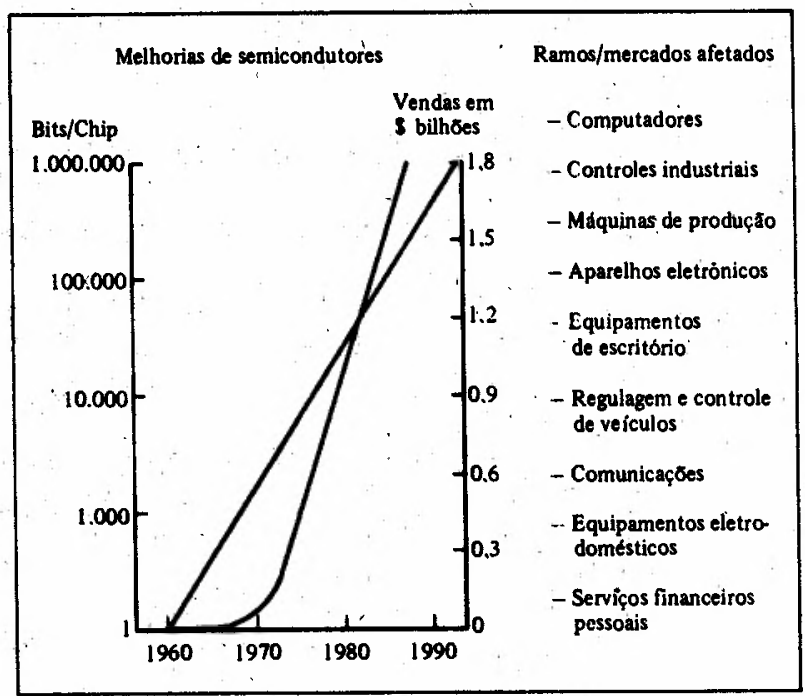

Neste processo, a indústria de semicondutores, que afetou profundamente outros setores, está sendo, ela própria, reformulada.

A tendênciia atual é concentrar-se mais na configuração de solução dos problemas sob a forma de sistemas, com menos ênfase no design de componentes. Desta forma, mais conhecimentos de aplicação e de desenvolvimento da capacidade de elaborar o software estão sendo integrados nas empresas de produção de microprocessadores, induzindo os fabricantes de componentes a tornar-se também empresas de "sistemas". 
d) a emergência de novas indústrias e mercados: as mudanças tecnológicas criam também novos e amplos mercados, bem como indústrias completamente novas, tais como os equipamentos baseados em energia solar, drogas de base biológica, bancos de dados e sistemas de informaçס̃es domiciliares, computadores pessoais, combustíveis sintéticos e outros materiais artificiais e sintéticos.

0 pleno desenvolvimento das tecnologias que influenciam a criação desses mercados pode levar 10 anos ou mais. Contudo, uma vez iniciado o processo de sua comercialização, a nova tecnologia emerge com rapidez, ameaçando e, eventualmente, expulsando a tradicional, anteriormente em uso, para a surpresa de muitas firmas desprevenidas.

A figura 3 mostra a emergência de duas tecnologias que criaram indústrias completamente novas, em espaços de tempo relativamente curtos. Ressalta-se a rapideż com que a tecnologia se torna comerciável, uma vez iniciada a difusão e aplicação em larga escala.

Figura 3

Os rumos e o ritmo do desenvolvimento tecnológico podem ser antecipados

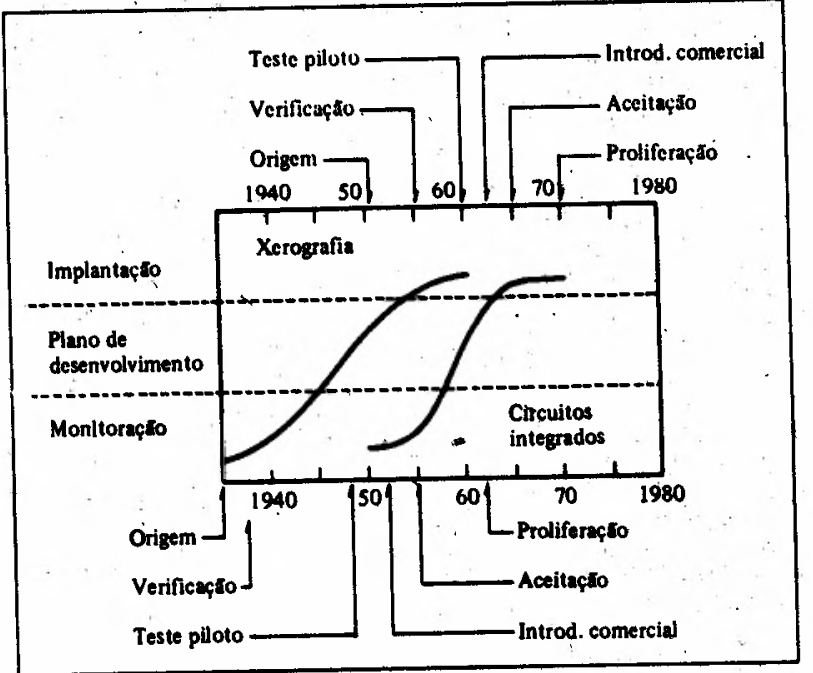

Parece haver uma diferença fundamental entre os anos 60-70 e o período atual dos 80: embora o desenvolvimento de uma tecnologia leve muitos anos, sua ta$x a$ de difusáo é bem mais rápida agora, passando-se da fase de desenvolvimento para a plena implementação em poucos anos. Uma vez testada em uma indústria, a aplicação da nova tecnologia prolifera em novos produtos, em outros ramos, quase tão rapidamente quanto a sua emergência nas aplicaçőes iniciais.

Este parece ser o caso do grande mercado para equipamentos médicos eletrônicos, no qual o semicondutor, o computador e a tecnologia de projeção visual convergem para proporcionar um potencial muito vasto de diagnóstico. Exames médicos, antes impossíveis de serem realizados, são executados agora pelo uso de novas tecnologias, alimentando o mercado para equipamentos de diagnóstico complexos, em rápida expansão.

Em que pese aros elevados riscos inerentes aos mercados de tecnologia novos, estes oferecem também grandes lucros para as empresas que conseguem ocupar cedo posiçőes de proprietárias das teçnologias emergentes, e defendê-las, com sucesso, contra as invesțidas dos potenciais concorrentes.

e) o desenvolvimento de mercados e da concorrência em escala global: a tendência recente e bem documentada para a criação de mercados em escala mundial foi poderosamente estimulada pela aplicação de tecnologia de ponta. Mercados para estas tecnologias devem ser, necessariamente, globais em sua dimensão, porque uma demanda em nivel mundial é indispensável para justificar investimentos necessários para seu desenvolvimento.

A figurá 4 mostra os custos de desenvolvimento para um novo eqúipamento médico eletrônico. Os resultados da análise demonstram que enquanto o fabricante não expandir sua distribuição e seu marketing para o mercado mundial, ele corre o perigo de custos de desenvolvimento - em termos percentuais das vendas - elevados demais para recuperar seu investimento em P \& D.

As curvas mostram, também, que no caso de 0 produtor conseguir capturar uma fatia maior do mercado mundial ( 30 a $40 \%$ ), qualquer concorrente terá dificuldades para manter um nivel de investimentos suficientes, para não perder terreno com relação ao lider do ramo. Assim, uma aplicação bem-sucedida de tecnologia constitui uma barreira estratégica poder̦osa a favor da empresa que conseguiu conquistar uma fatia maior do mercado mundial. Se não for possível superar esse impasse mediante licenciamento de tecnologias-chave ou a formação de joint-venture com a empresa líder da tecnologia emergente, alcançá-la ou igualá-la torna-se uma tarefa praticamente impossível, pois os seguidores deverão investir em $P$ \& D aproximadamente os mesmos valores destinados por aquela. Esta política, além de arriscada, pode tornar-se ruinosa para as empresas cuja participação no mercado é pequena demais para sustentar esse esforço de investimento.

Figura 4

Altos custos do desenvolvimento tecnológico criam barreiras à entrada nós mercados

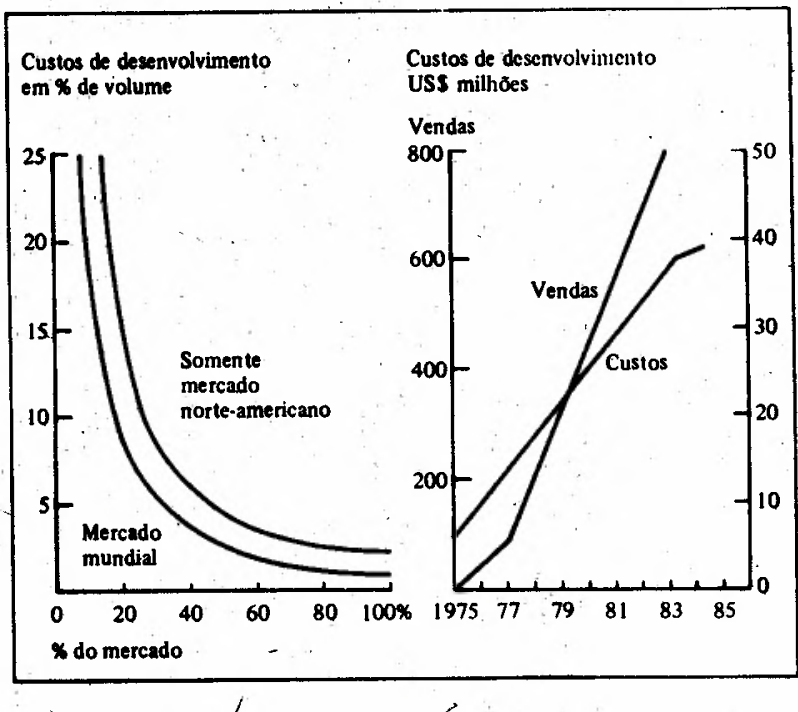

f) o nacionalismo tecnológico: a tendência em direção ao "nacionalismo tecnológico" está se generalizando de forma crescente nos países desenvolvidos e no Terceiro Mundo. Os governos estão patrocinando diretamente 
empresas que entram nos mercados globais e proporcionam incentivos explícitos àquelas que, baseadas em seu território, contribuem para expandir as exportações e o nivel de emprego.

As formas de patrocínio variam, desde empresas protegidas $\mathrm{e}$ incentivos à exportação até 0 apoio declarado a projetos de joint-venture govemo-empresa em programas comerciais (exportação) e de P \& D. Reserva de mercado ou proibição de importações, além de incen. tivos e isenções de taxas e impostos, constituem um elenco de medida e instrumentos adotados pelos governos para estimúlar a criação de emprego e a conquista de mercados externos, enquanto procuram proteger as indústrias nacionais contra os concorrentes baseados no exterior.

Tanto o governo francês - através de suas diretrizes no campo da "telemática" e da indústria automobilística - como o japonês - na área de materiais sintéticos, semicondutores, robôs etc. - e outros govemos europeus nas indústrias aeroespacial, química e cosmética, proporcionam decidido apoio às grandes empresas, na expectativa de que ganhem posiçōes competitivas nos respectivos mercados globais.

Desnecessário, talvez, acrescentar que tais políticas tendem a aumentar as contradiçōes e conflitos, antes travados entre empresas, a nivel internacional, agravando as tensōes políticas num mundo finito e incapaz de abrigar e permitir o desenvolvimento harmonioso de dezenas de regimes nacionalistas, praticando políticas neomercantilistas extremadas.

Em resumo, a concorrência entre os oligopólios tende a acirrar-se à medida que entrantes, aplicando novas tecnologias, na década de 80 , conseguirem deslocar empresas trabalhando com tecnologias convencionais, contando inclusive com 0 apoio de seus respectivos governos, preocupados com os problemas de emprego, balanço de pagamentos e estabilidade social e política.

Vários setores despontam como prováveis arenas de confronto e conflitos:

- máquinas-ferramenta, onde fabricantes de computadores tentarão competir com os produtores atuais desses equipamentos, para assumir a liderança na fabricação de máquinas automatizadas, robós e de sistema do tipo Icam (integrated computer aided manufacturing);

- recreação a domicílio, em que as empresas de telecomunicaçðes e de equipamentos eletrônicos lutarão por fatias do mercado com os produtores de bens de consumo eletrônicos e de programas de rádio e televisão; - bens de consumo: empresas que prestam serviços financeiros, tais como bancos e cartōes de crédito, competirão com as grandes lojas de varejo pelas vendas a domicrilio e outros serviços aos consumidores;

- informática: empresas proprietárias de redes de computadores e de bancos de dados orientados para consumidores podem tornar, facilmente, as empresas editoras e a imprensa atual obsoletas.

Com referência às diretrizes estratégicas dos oligopólios e grandes conglomerados é possível antecipar o seguinte:

- os investimentos serão mais concentrados em "produtos de propriedade" que em produtos-mercadorias (com- modities), por constituírem aqueles a chave de elevados lucros nos anos 80, pelas vantagens na fixação dos preços, decorrentes de "prâticas monopolistas". Por outro lado, constituirá estratégia de alto risco o desenvolvimento de produtos cuja tecnologia pode facilmente ser copiada por países que procuram "nacionalizar" seus mercados. A tentativa de tornar-se fabricante a mais baixo custo de determinado tipo de produto-mercadoria exigirá, cada vez mais, enormes quantias de capital e plantas em escala mundial, enquanto implica grande vulnerabilidade à mudança de preços devida à escassez e elevação dos custos das matérias-primas, à alteração das políticas nacionais de recursos naturais, de custos de capital, de remuneração da máo-de-obra etc. No caso de continuar com produtos-mercadorias, a ênfase nos investimentos deve incidir naqueles em que a empresa terá vantagens de custo comparativas, além de fontes de abastecimento seguras de matérias-primas e uma capacidade de distribuição em mercados globais;

- em muitos dos mercados (indústrias) de tecnologia de ponta, as empresas terão de aprender a atuar e a competir em mercados globais, tal como já está ocorrendo nos setores de telecomunicação, automobilística, computadores, equipamentos eletrónicos etc. Outros, ramos, tais como máquinas-ferramenta e equipamentos de escritório, seguirâo o mesmo caminho. $\mathbf{O}$ desafio maior para as empresas conquistarem e manterem-se nos mercados globais será a capacidade de desenvolver seus sistemas de distribuição e de marketing em escala internacional; - a "entrada nos mercados globais terá de ser efetuada quanto antes, pois, caso contrário, os custos de P \& D para alcançar os concorrentes podem tornar-se ruinosos para os que se atrasam. A conquista de uma fatia substancial do mercado global pode constituir-se em barreira aos concorrentes, pois permite a diluição dos gastos em P \& D por produtos comercializados em mercados mundiais;

- e será que as empresas incapazes de competir nos mercados globais poderão manter-se nos mercados nacionais? Ou terão de contentar-se com os "nichos" do mercado, sem interesse para os concorrentes que atuam em escala global?

Parece que a "conquista" de determinadas tecnologias não garante a sobrevivência das empresas nacionais, pois certos ramos, mesmo quando orientados para "produtos de propriedade", se revelam incapazes de proporcionar retornos adequados sobre os investimentos (por exemplo: a geração de energia nuclear);

- os custos cada vez mais elevados dos investimentos em P \& D exigirão a criação de consórcios ou cooperativas, alterando fundamentalmente a estrutura e os mecanismos dos negócios;

Devem-se prever, também, dificuldades crescentes no licenciamento e na transferēncia de tecnologia, pelas implicaçóes que terão em termos de concorrência na luta pelos mercados globais. Nenhum tratado ou código de conduta intemacional poderá alterar a realidade da dinâmica de acumulação e expansão do sistema capitalista, o que implica, a nível das empresas, a necessidade de integrar a variável tecnológica ao processo de planejamento estratégico da organização, e a nivel de governo, a formulação e execução de uma política científico-tecnológica explícita. 


\section{MUDANÇAS NO PROCESSO E NA ADMINISTRAÇĀO DE EMPRESAS}

A padronizaçฐ̃o dos equipamentos microeletrônicos influenciará profundamente as estruturas produtivas. A produção e comercialização de grandes quántidades de microprocessadores, memorias e instrumentos de controle ligados a terminais periféricos permitirão a fabricação de milhoes de "caixas-pretas" a custos mínimos e cuja aplicaçáo será orientada por um software específico insumo de "caixapreta" - a ser acopląda a determinado equipamento para operação e controle.

A fabricação dessas "caixas-pretas" concentrar-se-á provavelmente nas mãos de alguns grandes produtores mais avançados na miniaturização dos circuitos integrados. Outras empresas tenderão a especializar-se na oferta de software, de acordo com as necessidades específicas dos consumidores. Em ambos os casos, é bastante provável a eliminação de pequenas e médias empresas concorrentes.

A elevação da taxa de inovação na microeletrônica reduz, de fato, o ciclo da vida dos produtos, e exige, por isso, mais flexibilidade na organização da produção. Acrescenta-se o abandono progressivo das esteiras rolantes convencionais, substituídas por estruturas mais integradas, que alteram profundamente a produção. Esta evolução exige recursos mais elevados para $P$ \& D, a fim de manter-se em dia com o ritmo de inovaçóes do mercado: enquanto os produtores de equipamentos mecânicos para escritórios destinam 1 a $2 \%$ do faturamento a P \& D, os novos equipamentos eletrônicos requerem uma verba correspondente de 6 a $10 \%$.

Experiências com plantas plenamente automatizadas e integradas estão em andamento (Icam = integrated computer - aided - manufacturing). Trata-se de fábricas que produzem pequenos lotes de produtos diferentes, com as mesmas máquinas: pequenas séries de máquinasferramenta de comando numérico, alimentadas por robôs e comandadas por minicomputadores, os quais estão ligados ao computador central que régula o ritmo da produção e o suprimento de materiais. Controle de qualidade e manutenção de rotina são confiados a robôs, enquanto eventuais interrupçōes podem ser resolvidas pelo computador central, capaz de reorganizar o plano e o fluxo de.produção.

Essas fábricas, embora reduzam radicalmente o número de operários, exigem mão-de-obra altamente qualificada para as tarefas de planejamento global (engenhejros analistas de sistemas), engenheiros que supervisionam a produção computorizada e técnicos para as linhas de -produção e manutenção dos equipamentos.

Verifica-se, assim, o deslocamento de responsabilidades e de poder decisório para a alta administração, em detrimento da relativa autonomia dos níveis subalternos.

A automação penetra inicialmente nas indústrias baseadas em processos de produção contínuos, tais como a química, siderúrgica, cimento, papel e celulose, nas quais o grande computador central constitui a base do sistema.

Os sistemas de planejamento e controle de produção mais modernos, baseados em microprocessadores distribuídos pelas principais seçð̄es da fábrica, elevam assim a capacidade operacional da planta e sua produtividade.
A introdução de máquinas-ferramenta de comando numérico levou à redução dos custos, volume e peso dos equipamentos; simplificou a produção, embora ampliasse a versatilidade e reduzisse os problemas e gastos com a manutenção. Centros de usinagem, tornos e fresadeiras de comando numérico já estão amplamente difundidos e em uso, e, com o acoplamento de microprocessadores aos robôs, os processos completamente automatizados se tornam realidade. Transformaçð̃es ainda mais radicais prenunciam-se nos setores bancário e comercial.

Caixas registradoras integradas por terminais, ligadas a leitoras de preços e sistemas de contabilidade on-line, bem como os sistemas de controble de estoque, marcação de preços e compras plenamente automatizadas, favorecem as tendências à concentração do comércio, com a conseqüente eliminação das pequenas e médias empresas e a redução do nivel de emprego.

A penetração da nova tecnologia baseada na microeletrônica far-se-á sentir também nos serviços de escritório que, até recentemente, têm-se mantido à margem.das inovaçठes. $O$ baixo índice de investimentos, a fim de elevar a produtividade dos white collar, tende a aumentar à medida que o enfoque na análise do processo de trabalho passa a ser transferido da secretária para o executivo. Também, o aumento do custo da força de trabalho, enquanto diminuem os custos dos equipamentos, induzirá a automação dos serviços clericais, com maior uso de processadores de textos e equipamentos de reprodução. Pesquisas estão sendo desenvolvidas, visando à fusão de informaçōes de dados, textos, vozes e imagens, em documentos eletrônicos integrados, que podem ser comunicados, armazenados e recuperados, com base em sistemas de geração e distribuição de informaçōes, comandados por computador.

Outro aspecto importante na busca de melhorar as comunicaçōes nos escritórios é representado pelo tratamento do fator humano, a nível do sistema administrativo, ou seja, a adequação das estruturas da rede de informação às necessidades da organização concreta.

No início da introdução de processamento de dados, - computador foi colocado atrás de parede de vidro, comandado a serviço de uma autoridade central. Posteriormente, foi introduzido o "tempo compartilhado" (time sharing) no qual o computador servia a todas as unidades da empresa, através de linhas de comunicação teleprocessadas, porém ainda preso à estrutura de autoridade formal da organização, segundo as linhas de seu organograma.

$O$ desenho de redes e sistemas flexíveis permite 0 fluxo de informação e sua adaptação às organizações concretas e as necessidades de seu pessoal, em vez de forçar a conformidade com uma estrutura artificial. Uma rede de computadores moderna terá capacidade de refletir tanto as relações informais quanto as estruturas formais, sendo que, no primeiro caso, o fluxo de trabalho e de informação procede sem qualquei controle nodal, enquanto no segundo estarão em uso redes sofisticadas, direcionadas de cima para baixo, com um controle central bastantc rígido. $O$ grau de utilização de um ou outro sistema pode variar de uma organização para outra, mas, em princípio, formas de ampliação diferentes deveriam coexistir, dentro do sistema básice de transmissão da organizaçáo. 
Convém frisar, a título de llustractó, que uma determinada corporação transnacional dispoo de um serviço de comunicação interno que liga mais de 500 computadores, espalhados em 100 cidades situadas em 18 paises, tendo-se ampliado a rede à razão de um computador por semana, durante os últimos anos. ${ }^{1}$ Em síntese, 0 processo contínuo de acumulaç⿸厃㔾 de capital, que passou a funcionar em escala global, encontra nos sistemas computadorizados de processamento e comunicação de informaçós os instrumentos adequados para as novas formas de organização emergentes de produção, de marketing e de $P \& D$, planejadas e conduzidas em dimensóes internacionais e, a mesmo tempo, utiliza a nova tecnologia para aumentar a produtividade, reduzindo assim o custo das operaçóes que envolvem trabalho humano.

Somando os desempregos da indústria, agricultura e dos outros ramos de serviços, em consequééncia das aplicaçöes crescentes da microeletrônica, estaremos numa encruzilhada - talvez a mais crítica da história da humanidade, na época moderna. A medida que diminuem as oportunidades e, eventualmente, a necessidade de se trabalhar, pelo menos nos paises mais industrializados, permanece e recrudesce o problema do "sentido da vida", ou como substituir o trabalho considerado essenncia e centro da vida, nas sociedades baseadas no ethos judaico-cristão, por uma nova orientação de valores, sem provocar o desmoronamento da cultura ocidental?

\section{A NNOVAÇÃO TECNOLOGICA E AS PEQUENAS E MEDIAS EMPRESAS (PME)}

A concorréncia entre os oligopólios tende a acirrarse, e nzo somente por razoes conjunturais, I medida que as empresas transnacionais (ETN) entram em mercados com suas novas tecnologias e conseguem deslocar empresas que trabalham com tecnologias convencionais, contando inclusive com o apoio dos governos dos países em desenvolvimento que estão preocupados com os problemas de balanço de pagamentos, geração de empregos e 0 crescimento economico em geral. Mas as empresas que náo têm condiçőes de competir em mercados de escala global - as pequenas e médias empresas nacionais - será que podem manter-se nos mercados nacionais-invadidos pelas ETN, ou terăo de contentar-se com os "nichos" de mercado, sem interesse para os grandes concorrentes que atuam a nivel global?

Os custos cada vez mais elevados dos investimentos em P \& D parecem afastar as PME de possibilidades de inovação tecnológica e, portanto, de concorréncia nos mercados, a năo ser que resolvam criar consórcios ou cooperativas, 0 que tenderia a alterar fundamentalmente a estrutura e os mecanismos dos negócios. Por outro lado, devem-se prever dificuldades e problemas crescentes na transferência de tecnologia, dadas as implicaçoes que esta tem na concorrència e na luta pelos mercados. A análise das relaçóes existentes entre a organização da base técnica da indústria (do ramo) e as formas de concorrência leva à constatação de que, para certos ramos de atividade, as inovaçóes tecnológicas săo exógenas, ou seja, são produtos de P \& D realizados em outros ramos da economia.
O caso típico e o da indústria téxtil que se caracteriza pela incorporação de inovação dos fabricantes de equipamentos e da indústria química. Os efeitos desta situaçróo š̃o mulltiplos: $O$ acesso ds inovaçరes é facilitado as empresas concorrentes, sem que estas tenham condiçóes privilegiadas para influir diretamente na política e nas diretrizes de $P$ \& D. A auséncia do domínio absoluto do "progresso técnico" no ramo torna as empresas, mesmo as maiores, vulneráveis e sujeitas à perda rápida de fatias de mercado.

Nos ramos dominados por oligopólios que controlam o processo de inovaçto mediante uma politica agressiva de $P$ \& $D$, esta se toma mecanismo básico para assegurar a posiçzo líder no mercado.

Para melhor configurar a dinâmica do processo, convém distinguir entre inovaçóes primárias re secundárias; representando as primeiras mudanças profundas da tecnologia corrente, enquanto as segundas se caracterizam com alteraçoes relativamente pequenas dos processos e/ou produtos, visando a melhorar a qualidade destas ou a produtividade do trabalho.

Inovaçбes primárias implicam, portanto, grandes investimentos para substituir máquinas e equipamentos tornados obsoletos, que as empresas lideres do ramo procuram postergar até onde for possível, enquanto næ̃o tiverem amortizado as imobilizaçסes realizadas na base técnica anterior. A consequiéncia lógica dessa diretriz é a enfase em P \& D que resultem em inovaçőes secundárias. Somente com a generalizaçæo da inovaç̃o e sua adoçăo pela maioria das empresas concorrentes no ramo haverá estímulo e incentivo para os líderes financiarem novos projetos de pesquisa, apesar dos riscos e incertezas a eles inerentes.

Atividades de P \& D sistemáticas tomam-se, portanto, condição sine qua non para a' sobrevivência das empresas que ocupam posiçăo de líder em qualquer oligopólio. Por isso, seria ilusório esperar que as ETN entreguem graciosamente, aos seus concorrentes potenciais, o instrumento estratégico para sua expansão.

Ao contrário, para obter maior retomo sobre seus investimentos, sem correr o risco de imobilizaçбes adicionais nos paises do Terceiro Mundo, todos inadimplentes, as ETN póem em execução uma nova política que visa a consecuçróo de ganhos mediante os pagamentos a titulo de fornecimento de know-how, de peças, componentes e de assistência técnica. Neste caso, a renda é constituida por royalties, e os mercados antes inacessiveis - como, por exemplo, os paises do leste europeu sáo paulatinamente penetrados e ocupados, sem enfrentar os problemas de escassez de capital, de reivindicaçб̃es trabalhistas ou de ressentimentos nacionalistas, que agravam os riscos e a incerteza dos investimentos, inclusive nos NIC.

Os recursos assim liberados são concentrados nas atividades de P \& D e de marketing em escala global, 0 que concorre para fortalecer a capacidade de expansťo e de penetração em novos mercados das ETN, elevando seus lucros e estimulando, numa espécie de "ciclo virtuoso", seu crescimento.

A expansto contínua dos conglomerados e empresas transnacionais tende a introduzir profundas modificaçסes na divisão intemacional de trabalho que, por sua vez, afetam invariavelmente 0 processo de industrialização nos NIC. A industrialização por substituição das impor- 
taçðes tinha alterado a divisão de trabalho tradicional entre países industrializados e produtores de matériasprimas e alimentos, permitindo o acesso, ainda que mo desto, destes últimos aos mercados de produtos manufaturados, através do fornecimento de bens de consumo, mão-de-obra intensivos (produtos têx teis, calçados etc.). A base tecriológica dessas indústrias é constituída, essencialmente, por máquinas e equipamentos eletromecânicos e processos de trabalho semicontínuos.

A crescente tecnificação da produção, impulsionada por inovaçóes produzidas em laboratórios e centros de P \& D controlados pelas ETN, coloca em pauta o problema da sobrevivência das empresas formadas nos NIC, com uma base tecnologica que se toma rapidamente obsoleta, embora seu custo ainda não tenha sido amortizado e as dívidas contraídas para sua aquisição continuem a onerar pesadamente o balariço de pagamentos.

A nova tecnologia baseada nos circuitos integrados e equipamentos microeletrônicos variados altera a composição orgânica do capital e elimina empregos que exigem qualificaçōes convencionais. O quase-monopólio obtido pelo controle de "produtos-propriedade" e a administração de preços praticada pelas ETN permitem manter ou até aumentar a taxa de lucro. Por outro lado, o planejamento e a estratégia globais dos conglomerados tendem a substituir os mercados por transaçoes inter e intracompanhias em escala internacional, sendo o controle sobre os subsistemas exercido pela matriz, mediante um complexo sistema de comunicação e processamento de informações, que reforçam e tornam mais eficaz o processo decisório da alta direção das ETN. A conseqüente conquista e o controle de mercados nos NIC pelas ETN criam uma situação e condições de atuação e de sobrevivência diferentes para as PME, cujos vetores devem ser equacionados e integrados à administração empresarial e à política econômica $\mathrm{e}$ industrial do Estado.

Por outro lado, deve-se examinar criticamente a viabilidade de adaptações das tecnologias importadas, a fim de atender as necessidades e expectativas do país, no que se refere à criação de empregos e à absorção e assimilação de tecnologias modernas, em busca de sua maior autonomia.

Estudos empíricos recentes ${ }^{2}$ apontam para os limites estreitos na escolha de tecnologias e suá adaptação às condiçōes específicas do país em desenvolvimento, uma vez definido o produto e dimensionado o mercado a ser atendido, embora se verifiquem grandes variações, de um ramo ou setor para outro.

Em ramos de "baixa tecnologia" produzindo bens convencionais e pouco sofisticados, como por exemplo, a indústria têxtil, a gama de opçőes tecnológicas é relativamente ampla. Existem técnicas de produção tradicionais e a demanda dos diversos extratos de renda varia em termos de padrōes de sofisticação e qualidade dos produtos, o que permite soluções tecnológicas diferentes. No caso de exportação para os países desenvolvidos, as opções tecnológicas se estreitam, em função de requisitos de qualidade específicos.

Em ramos de "tecnologia de ponta" (autopeças, por exemplo), os requisitos de qualidade do produto, inclu: sive suas peças e componentes, são caracterizados por tolerâncias mínimas, impondo-se, destarte, escalas de produção, equipamentos, matérias-primas e prócesso de fabricação utilizados na matriz das ETN, nos paỉses desenvolvidos. $O$ planejamento e a programação da produção visarão, nestes casos, a reduzir as dimensões do estabelecimento para adaptá-lo à demanda do mercado local ou regional.

As ETN se concentram, geralmente, nos ramos onde há pouca concorrência das empresas nacionais, pela tecnologia superior que se utiliza na fabricação. Para os produtos fabricados com tecnologia/ relativamente simples e mão-de-obra intensiva, as ETN preferem recorrer à subcontratação, mantendo assim as PME subordinadas e dependentes.

A divisão de trabalho que se estabelece entre as ETN e as PME que atuam num mesmo ramo (por exemplo, indústrias automobilísticas) explica os diferentes níveis tecnológicos e, portanto, de intensidade de mão-de-obra encontrados em empresas de um mesmo grupo de classificação. A produção de peças e componentes exige máquinas e equipamentos modernos, enquanto a mon tagem final dos mesmós é geralmente realizada manualmente, por processo de mão-de-obra intensivo. Outro fator determinante da tecnologia e da intensidade de mão-deobra é representado pelo mercado de destino do produto. Pressionadas pelos governos dos paises em desenvolvimento, as ETN, procurando exportar pelo menos parte de sua produção, são obrigadas a zelar por padrões de qualidade superiores, obtidos com o emprego de maquinaria mais sofisticada.

A entrada de ETN e seus impactos em termos de emprego devem ser analisados e avaliados em função dos ramos específicos e de suas condições estruturais, econòmicas e institucionais. Em alguns casos (por exemplo, autopeças), as ETN montadoras induzem, indubitavelmente, a criação de inúmeros empregos, "para-frente" e "para-trás", sob forma de subcontratação da produção de insumos, peças e componentes, bem como a execução de serviços indispensáveis para seu funcionamento. Em outros (por exemplo, a indústria de tecidos sintéticos ou de calçados plásticos), os efeitos são provavelmente negativos, não somente pela eliminação dos produtores baseados em materiais e tecnologias tradicionais, mas também de seus fornecedores que perdem seus clientes. Finalmente, verificam-se os casos de compra ou incorporação de empresas nacionais por ETN, com sua posterior racionalização e a conseqüente demissão de empregados.

Tentando resumir sobre a penetração das ETN e sua atuação na economia brasileira, verifica-se que sua conduta e, portanto, seu impacto sobre as PME de seus respectivos ramos são determinados pelas escalas do mercado, o desenvolvimento da infra-estrutura e das indústrias de apoio e, sobretudo, por toda um série de fatores sócio-políticos, inclusive as políticas econômica e industrial postas em prática pelo governo. O controle estrito das organizaçóes sindicais e de suas reivindicações em termos de política salarial e previdenciária pode constituir um poderoso fator de atração das ETN, bem como os esquemas generosos de isençð̄es e incentivos fiscais tributários, especialmente para as empresas exportadoras, implantados e mantidos desde os anos do "milagre" brasileiro. Nesses casos, dependendo obviamente da gama de produtos e seus respectivos mercados, as opções tecnológicas para as ETN e seus efeitos sobre as PME, o nível de emprego e o desenvolvimento de um potencial tecnológico relativamente autônomo são bastante limi- 
tados, sobretudo nos ramos que operam com tecnologias de ponta. Independentemente de sua origem nacional, seria irrealista a expectativa de sacrificarem as ETN a vantagem da liderança tecnológica, a fim de favorecer o desenvolvimento do país hospedeiro. Uma alternativa mais concreta seria uma triagem cuidadosa das propostas de ingresso no país das ETN, com base numa antecipação de seus efeitos diretos e indiretos.

Entretanto, para poder decidir sobre ramos ou setores que estariam abertos à entrada das ETN e as escalas de produção mais "apropriadas" em função das necessidades do país, o governo necessitará basear suas decisర̃es em projeçōes da evolução das indústrias, sua demanda por mão-de-obra, os mercados potenciais, as matériasprimas e tecnologias a serem desenvolvidas. Isto implica, por sua vez, atividades de $P \& D$ e de monitoraçáo permanentes. $O$ acesso à informaçáo sobre as alternativas tecnológicas permite ao governo negociar em condiçб̄es mais favoráveis com as ETN, quanto à adequação dos produtos e métodos de produção que pretendem introduzir nos NIC. Somente após um processo de análise criteriosa e de triagem das propostas das ETN, uma politica industrial orientada para as PME se torna viável e eficaz, na medida em que tende a estimular as relaçðes "para-frente" e "para-trás", com esquemas de apoio financeiro, formação de mão-de-obra e de $\mathrm{P} \& \mathrm{D}$, a serviço das pequenas e médias empresas nacionais:

1 Ver Branscomb, L. M. Electronics and computers: an overview. Science, 215: 755-60, 1982.

2 Ver Watanabe, S. Multinational enterprises, employment and technology adaptations. International Labour Review. Genebra, 120. (6), 1981.

\section{BIBLIOGRAFIA}

Brascomb, L. M. Electronics and computers. Science, $215 ; 755-60,1982$.

Bessant, J. et alii. The impact of microelectronics: a review of the literature. London, Francis Pinter, 1981.

Guimarăes, E. A. Acumulaçāo e crescimento da firma. Rio de Janeiro, Zahar, 1982.

Hudson, C. A. Computers in manufacturing, Science, 215, 12 Fev. 1982.

Lecrae, D. J. Technological activity of less developed country - based multinationals. The American Academy of Political and Social Sciences, Annals, 458, Nov. 1981.

Morehouse, $W$. The microelectronic revolution and North-South relations in the 1980's. In: Szyliowicz, J. S., ed. Technology and international affairs. New York, Praeger Scientific, 1981.

Morley, S. A. \& Smith, G. W. Adaptation by foreign firms to labour abundance in Brazil. In: Street, H. \& fa mes, D. D. Technological progress in Latin America: the prospects for overcoming dependency. Boulder, Colorado, WestviewPress, 1979.

Rada, J. The impact of microelectronics and information technology. Reference to Brazil, Argentina and Bolivia. Genebra, Unesco, 1980.

Rattner, H. Acumulaçāo de capital, internacionalizaçāo da economia e PME. Relatório de pesquisa. EAESP/ FGV, 1982, mimeogr.

Watanabe, S. Multinational enterprises, employment and technology adaptations. International Labour Review, Genebra, 120:(6), 1981.

Zelenovic, D. M., ed. Effectiveness, quality and humanity of production systems: Proceedings of the VI International Conference on Production Research. Novi Sad, Iugoslavia, 1981.

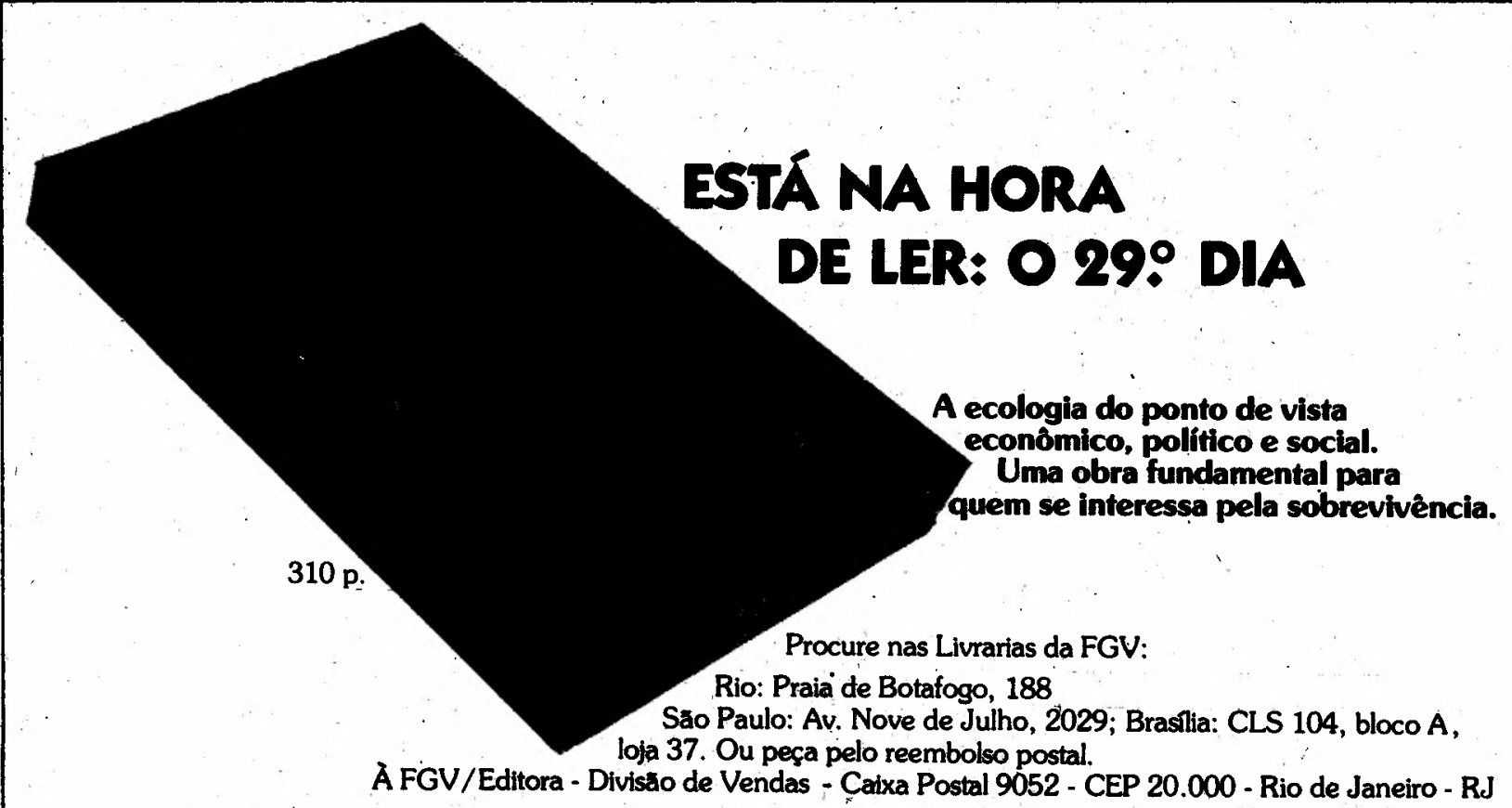

